\title{
Küresel İnovasyon Endeksine Göre Orta Asya Türk Cumhuriyetlerinin Mevcut Durumu ${ }^{1}$
}

\author{
The Current State of The Turkic Republics According to The Global Innovation Index
}

\author{
Hasan GÜL \\ Prof.Dr., Ondokuz Mayls Üniversitesi, IIIBF \\ hasan.gul@omu.edu.tr \\ https://orcid.org/0000-0002-3720-5451
}

\author{
Azamat MAKSÜDÜNOV \\ Yrd.Doç.Dr., Kırgızistan - Türkiye Manas Üniversitesi, IIBF \\ azamat.maksudunov@manas.edu.kg \\ https://orcid.org/ 0000-0002-5010-513X
}

\author{
Aysuluu BEYŞENOVA \\ Ö̆rr.Gör., Kirglzistan - Türkiye Manas Üniversitesi, MYO \\ aysuluu.beyshenova@manas.edu.kg \\ https://orcid.org/ 0000-0002-9485-647X
}

Makale Başvuru Tarihi / Received: 17.11.2021

Makale Kabul Tarihi / Accepted: 13.12.2021

Makale Türü / Article Type: Araştırma Makalesi

Anahtar
Kelimeler:
Inovasyon,
Küresel Inovasyon
Endeksi,
Türk
Cumhuriyetleri.

Keywords:

Innovation,

Global Innovation Index,

Turkic Republics.

\section{ÖZET}

Günümüzde her alanda ekonomik büyüme ve teknolojik rekabetçilik için bilgi ve inovasyonun önemi gittikçe artmaktadır. Yapılan bu araştırmanın amacı, Orta Asya Türk Cumhuriyetlerinin inovasyon ile ilgili durumunu incelemektir. Bu amaçla her yll Dünya Fikri Mülkiyet Örgütü (WIPO), Cornell Üniversitesi ve INSEAD işbirliğinde hazırlanan 2015-2020 yıllarını kapsayan Küresel İnovasyon Endeksi raporlarından yararlanılmıştır. Çalışma Kırgızistan, Türkiye, Kazakistan, Azerbaycan, Özbekistan ve Tacikistan olmak üzere 6 ülkeyi kapsamaktadır. Araştırma sonuçlarının bu ülkelerdeki inovasyonla ilgilenen kurum ve kuruluşlar için önemli ve yararlı bilgiler sağlayacă̆ı düşünülmektedir.

\footnotetext{
${ }^{1}$ Bu çalışma 9-11 Haziran 2021 tarihinde düzenlenen II. Uluslararası İktisadi ve İdari Bilimler Kongresi'nde bildiri olarak sunulmuştur.
} 


\section{GIRIŞ}

Günümüzde her alanda hızlı bir değişim ve gelişim yaşanmaktadır. Dünya çapında küresel rekabetin artması, gelişmekte olan ülkelerin de hızlı bir şekilde uluslararası pazarlara katılmaya başlaması, eskiye göre tüketicilerin daha bilinçli olması, sosyal pazarlama anlayışı, sürekli gelişen teknoloji gibi eğilimler işletmeleri ulusal sınırları aşarak küresel düzeyde uzlaşmaya götürmektedir. Küresel çapta yaşanmakta olan rekabet ortamı ve teknolojik gelişmeler iş dünyasında inovasyon kavramını önplana çıkarmakta ve inovasyon işletmeler için temel rekabet avantajı haline gelmektedir.

İnovasyon kavramı hem araştırmacılar, hem de farklı endüstri dalları için ilgi uyandıran, karmaşık bir kavramdır. Bilim adamları ve farklı endüstriler, inovasyon tanımı ile ilgili birçok açıdan farklı yaklaşımlarda bulunmuşlardır. Müş̧eriler açısından inovasyon, daha kaliteli ve daha iyi hizmetlere sahip ürünler anlamına gelirken, çalışanlar için inovasyon, yeni ve daha ilginç bir iş anlamına gelmektedir. İşletmeler açısından ise inovasyon, sürdürülebilir büyüme ve gelişme anlamına gelirken, tüm ekonomi açısından üretkenlik ve refah anlamına gelmektedir (Gërguri vd., 2013: 12).

Ülkelerin inovasyonları teşvik edecek ortamı yaratmaları, bu konuda gerekli kaynakların sağlanması ve liderlik sorumluluklarının yerine getirilmesi önemlidir. Her ülkenin bu konuda yürütmekte olduğu değişik faaliyetler bulunmaktadır. Bu tür faaliyetlerin sonuçları ve ülkelerin inovasyon konusundaki performansları uluslararası derecelendirme raporlarına yansımaktadır. Konuyla ilgili küresel ölçekte yayınlanan çalışmalardan biri Küresel İnovasyon Endeksidir (Global Innovation Index, 2020). Bu çerçevede bu çalışmada ilk önce inovasyon kavramının tanımı ve öneminden bahsedilmiştir. Daha sonra, dünyada ülkelerin inovasyon performansını ölçen raporlardan biri olan Küresel İnovasyon Endeksine göre Orta Asya Türk Cumhuriyetlerin durumu ortaya konulmaya çalışılmıştır. Orta Asya Türk Cumhuriyetleri, Kırgızistan, Kazakistan, Özbekistan ve Türkmenistan olmak üzere beş ülkeyi kapsamaktadır. Bu çalışmada, Türkiye, Azerbaycan ve Tajikistan da birlikte ele alınmıştır. Türkmenistanın sözkonusu endekste yer almaması sebebiyle değerlendirme geriye kalan 6 ülke üzerinden gerçekleştirilmiştir.

\section{KAVRAMSAL ÇERÇEVE}

İşletmeler için rekabet avantajı sağlayabilmenin en iyi yolu inovasyondur. Günümüzde işletmeler benzer ürün veya hizmet sunan diğer işletmeler tarafından büyük bir baskı altında hareket etmektedirler. Diğer yandan, işletmeler tükettikleri üründen daha fazlasını bekleyen müşterilerin de baskısı altındadır. Yeni şartlar ve durumlarla başa çıkabilmek için işletmeler sürekli olarak yeni üretim yöntemleri aramaya, yeni ürünler üretme veya mevcut olanları geliştirme yoluna gitmek zorundadırlar. Başka bir deyişle, sürekli olarak "yenilikler" getirmeye ve geliştirmeye çalışmaktadırlar (Ramadani ve Gerguri, 2011: 101). Ancak, işletme tarafından yapılan her yenilik ilgili yazında tanımlanan inovasyon kavramını karşılamamaktadır. Bir icadın "inovasyon" olarak tanımlanabilmesi için örgüte "değer kazandrması" gerekmektedir (Ünal ve Kilınç, 2016: 100).

İş dünyasında inovasyonu tartışan insanlar inovasyon (yenilik), gelişme ve icat gibi üç farklı kavramı birbiriyle karıştırmaktadırlar. İnovasyon, Latince innovare fiilinden türetilmiştir. En basit tanımıyla inovasyon "farklı bir şey yapmayı" ifade etmektedir. Genellikle inovasyonlar riskli, maliyetli ve zaman alıcıdır. Öte yandan, iyileştirme daha iyi bir şey yapmak, icat bir fikir veya yöntem yaratma eylemidir (Costello ve Prohaska, 2013: 64). İnovasyon, genellikle teknolojik özelliklerle ilişkilidir ve dünya ekonomisinde kritik bir rol oynamaktadır (Baskaran ve Mehta, 2016).

İnnovasyon, aynı zamanda yeni fikir, ürün, cihaz veya yenilik olarak da açıklanabilmektedir. Günümüzde inovasyon, işletmeler için büyük önem arz etmektedir. İnovasyon bir süreç midir? Strateji midir? Bu bir kıyaslama (benchmarking) mı, çapraz işlevli bir ekip mi, yoksa dünya için yeni bir süreç mi? İnovasyon bir yönetim tekniği mi, yoksa liderlik sorumluluğu mu? Cevabı, inovasyon iyi yönetildiği zaman bir süreç, strateji, yönetim tekniği ve yukarıdakilerin daha fazlası olabilmektedir (Kuczmarksi, 2003: 536-537).

Joseph Schumpeter, inovasyonu yeni üretim fonksiyonuna veya yeni ürüne götüren bir faaliyet olarak tanımlamaktadır. Schumpeter'e göre inovasyon (McDaniel, 2002, 57-58):

1. Yeni bir ürünün sunumu - girişimci şu anda piyasada bulunmayan, ancak gelecekte kolayca 
sat1labilecek bir ürün üretmelidir.

2. Yeni bir üretim yönteminin tanıtılması - inovasyon, mevcut girdilerin değiştirilmesinin daha büyük çıktıya yol açabileceği, birim başına üretim maliyetinin düşürülebileceği veya mevcut girdilerin yerine yeni girdilerin kullanılabileceği farklı bir üretim planı sunmalıdır.

3. Yeni bir pazara açılması - inovasyonlar, yeni bölgelerdeki satışları ve müşteri sayısını artırmalıdır.

4. Yeni bir hammadde tedarik kaynă̆ının bulunması - genellikle, hammadde tedarikçisi zamanla hammaddelerin kalitesini düşürebilmekte veya fiyatlarını artırabilmektedir. Bu durum, doğrudan yeni ürünün kalitesini ve satış fiyatını da etkilemektedir. Bu nedenle, girişimci yeni ürünlerin üretimi için yeni tedarikçileri bulmaya çalışmalıdır.

5. Yeni bir endüstri organizasyonunun gerçekleştirilmesi - Schumpeter bunu daha önce rekabetin olmadığı tekel pazarına girişimcinin girişi veya girişimcinin pazardaki tekel konumunu alacağ 1 koşulların yaratılması olarak tanımlamaktadır.

İnovasyonların önemi ve tanımı çeşitli açılardan ele alınabilmektedir. Müşteriler açısından inovasyon, daha kaliteli ve daha iyi hizmetlere sahip ürünler anlamına gelmektedir ki, bu durum birlikte daha iyi bir yaşam tarzına kavuşma anlamına gelmektedir. İşletmeler açısından inovasyon, sürdürülebilir büyüme ve gelişme neticesinde büyük kârın gerçekleştirilmesini ifade etmektedir. Çalışanlar için inovasyon, daha fazla akıl kullanmayı gerektiren yeni ve daha ilginç bir iş anlamına gelmekte ve daha yüksek maaşlar almayı sağlamaktadır. Tüm ekonomi açısından, inovasyon herkes için daha büyük bir üretkenliği ve refahı temsil etmektedir (Gërguri vd., 2013: 12).

Geçmişten günümüze kadar inovasyon yeteneği her zaman bir kuruluşun başarısına katkıda bulunan en önemli faktörlerden biri olmuştur. Gerekli kaynakları dağıtan, inovasyon için güçlü bir motivasyonu sağlayan ve inovatif fikirlere izin veren ve inovasyonu teşvik edecek bir organizasyonel iklimi benimsenen işletmeler, tam olarak hızlı ve başarılı bir şekilde inovasyon yapacak organizasyonlardır (Popa vd., 2010: 151). Aynı, yaklaşımın ülke bazında da geçerli olduğu söylenebilmektedir. Ülkelerin inovasyonları teşvik edecek ortamı yaratmaları, bu konuda gerekli kaynakların sağlanması ve liderlik sorumluluklarının yerine getirilmesi istenilen inovasyon performansına ulaşabilmek açısından hayati önem arz etmektedir.

İşletmelerin inovasyon yapma motivasyonu çeşitli şekillerde ortaya çıkabilmektedir. Örneğin, pazar payını arttırma, yeni bir pazara girme, ürün kalitesinin yükseltilmesi, ürün yelpazesinin genişletilmesi, eski ürünlerin değiştirilmesi, çevre üzerindeki zararlı etkilerin azaltılması vb. Bunlar sistematik olarak yürütülmekte ve işletmenin tüm faaliyetlerini (araştırma- geliştirmeden başlayarak personelin faaliyetine kadar) kapsamaktadır. Yani, bir işletmenin tüm işlevleri ve faaliyetleri inovasyonun etkisi altındadır. İnovasyon faaliyetinin sonuçları yüksek kaliteli ürünler, mükemmel hizmet sunumu, yeni, daha verimli ve daha temiz (ekolojik) üretim süreçleri, çevreye daha az zarar verme, gelişmiş iş yönetim sistemi modelleri, modern iş gücü yönetimi yöntemleri vb. olarak ortaya çıkmaktadır (Ionescu ve Dumitru, 2015: 102). Genel olarak inovasyon, işletmeler için en iyi fikirlerin, en iyi çalışma yöntemlerinin ve hatta iş modellerinin ticari olarak uygulanmasını ifade etmektedir.

\section{KÜRESEL İNOVASYON ENDEKSİ VE ÖNE ÇIKAN ÜLKELER}

Küresel İnovasyon Endeksi (Global Inovation Index) projesi, Profesör Dutta tarafından 2007 yılında INSEAD görev süresinde başlatılmıştır. Amacı, araştırma makalelerinin sayısı ve araştırma ve geliştirme (AR-GE) harcamaları gibi geleneksel inovasyon önlemlerinin ötesine geçerek, toplumdaki inovasyonun zenginliğini daha iyi yakalayabilecek metrikleri ve yöntemleri bulmak ve belirlemek olmuştur.

$\mathrm{Bu}$ amaca ulaşmanın birçok nedenleri vardı. Birincisi, hem gelişmiş, hem de gelişmekte olan ekonomiler için inovasyon, ekonomik ilerlemeyi ve rekabet gücünü arttırmak için önemlidir. Birçok hükümet inovasyonu büyüme stratejilerinin merkezine koymaktadır. İkincisi, inovasyon tanımı genişlemiştir. Yani inovasyon artık Ar-Ge laboratuvarları ve yayınlanmış bilimsel makalelerle sınırlı değildir. Son olarak, her şeyden önce, gelişmekte olan pazarlarda inovasyonu tanımak ve kutlamak insanlara, özellikle de yeni nesil girişimcilere ve yenilikçilere ilham vermek için çok önemlidir.

Küresel İnovasyon Endeksi, inovasyon girdileri ve çıktıları olmak üzere iki alt endeksten oluşmaktadır (Tablo 1). İnovasyon girdi alt endeksi, beş alt bileşenden oluşmaktadır. Bunlar; kurumlar, insan sermayesi ve araştırma, 
altyapı, pazar gelişmişliği ve iş gelişmişliği' dir.

İnovasyon çıktıları, bir ekonomideki yenilikçi faaliyetlerin sonucudur. Çıktı alt endeksi, sadece iki alt bileşen (bilgi ve teknoloji çıktıları; yaratıcı çıktılar) içermesine rağmen, genel Küresel İnovasyon Endeksi puanlarının Girdi Alt Endeksi ile hesaplanmasında aynı ağırlığa sahiptir.

Tablo 1: Küresel İnovasyon Endeksi Çerçevesi

\begin{tabular}{|c|c|}
\hline \multicolumn{2}{|r|}{ İnovasyon Girdi Alt Endeksi } \\
\hline Kurumlar (Institutions) & $\begin{array}{l}\text { Politik Çevre (Political Environment), Düzenleyici Çevre (Regulatory } \\
\text { Environment), İş Çevresi (Business Environment) }\end{array}$ \\
\hline $\begin{array}{l}\text { Insan Sermayesi ve Araştırma } \\
\text { (Human Capital \& Research) }\end{array}$ & $\begin{array}{l}\text { Eğitim (Education), Yükseköğretim (Tertiarty Education), AR-GE (Research \& } \\
\text { Development) }\end{array}$ \\
\hline $\begin{array}{l}\text { Altyapi } \\
\text { (Infrastructure) }\end{array}$ & $\begin{array}{l}\text { Bilgi ve İletissim Teknolojileri (ICTs), Genel Altyapı (General Infrastructure), } \\
\text { Ekolojik Sürdürülebilirlik (Ecological Sustainability) }\end{array}$ \\
\hline $\begin{array}{l}\text { Pazar Gelişmişliği } \\
\text { (Market Sophistication) }\end{array}$ & $\begin{array}{l}\text { Kredi (Credit),Yatırım (Investment), } \\
\text { Ticaret, Rekabet ve Pazar Ölçeği (Trade, Competition \& Market Scale) }\end{array}$ \\
\hline 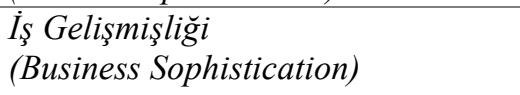 & $\begin{array}{l}\text { Bilgi Çalışanları (Knowledge Workers), İnovasyon Bağlantıları (Innovation } \\
\text { Linkages), Bilgi Absorpsiyonu (Knowledge Absorption) }\end{array}$ \\
\hline \multicolumn{2}{|r|}{ İnovasyon Çıktı Alt Endeksi } \\
\hline $\begin{array}{l}\text { Bilgi ve Teknoloji Çıktılarl } \\
\text { (Knowledge \& Technology Outputs) }\end{array}$ & $\begin{array}{l}\text { Bilgi Yaratma (Knowledge Creation), Bilgi Etkisi (Knowledge Impact), Bilgi } \\
\text { Dağılımı (Knowledge Difusion) }\end{array}$ \\
\hline $\begin{array}{l}\text { Yaratıcı Çıktılar } \\
\text { (Creative Outputs) }\end{array}$ & $\begin{array}{l}\text { Maddi Olmayan Duran Varlıklar (Intangible Assets), Yaratıcı Ürünler ve } \\
\text { Hizmetler (Creative Goods \& Services), } \\
\text { Çevrimiçi Yaratıcılık (Online Creativity) }\end{array}$ \\
\hline
\end{tabular}

Kaynak: The Global Innovation Index, 2020

Tablo 2'de Küresel İnovasyon Endeksine göre, dünya inovasyon liderlerinin sıralamasına yer verilmiştir. Görüldügü gibi, İsviçre 6 yıl üst üste Küresel İnovasyon Endeksinde birinci sırada yer almıştır. İsviçre inovasyon alanında 2020 yılında da "dünya liderliğini” korumaktadır. Bununla birlikte sıralanan listede gelişmiş ülkeler olan ABD, Singapur, Çin, İrlanda, Almanya gibi ülkelerin önde geldiği anlaşılmaktadır. Gelişmiş ülkelerin ekonomilerine genellikle biyoteknoloji, nanoteknoloji, bilgi ve diğer yenilikler hâkimdir. Araştırmalar, Japonya, Güney Kore, Tayvan, Hong Kong ve Singapur gibi ülkelerin innovasyon konusundaki yüksek performanslarını Batı ülkelerinin teknolojileri ve yönetim uygulamalarını kademeli olarak benimsemesiyle açıklamaktadır.

Tablo 2'ye bakıldığında inovasyonun daha çok yüksek gelirli ve gelişmiş ülkelerde gerçekleştirildiği görülmektedir. İlk 10'da henüz Türki Cumhuriyetlerden hiçbir ülke bulunmamaktadır.

Tablo 2: Dünya İnovasyon Liderleri (2015-2020)

\begin{tabular}{c|c|c|c|c|c|c}
\hline Sira & 2015 & 2016 & 2017 & 2018 & 2019 & 2020 \\
\hline 1 & İsviçre & İsviçre & İsviçre & İsviçre & İsviçre & İsviçre \\
\hline 2 & İngiltere & İsveç & İsveç & Hollanda & İsveç & İsveç \\
\hline 3 & İsveç & İngiltere & Hollanda & İsveç & ABD & ABD \\
\hline 4 & Hollanda & ABD & ABD & İngiltere & Hollanda & İngiltere \\
\hline 5 & ABD & Finlandiya & İngiltere & Singapur & İngiltere & Hollanda \\
\hline 6 & Finlandiya & Singapur & Danimarka & ABD & Finlandiya & Danimarka \\
\hline 7 & Singapur & İrlanda & Singapur & Finlandiya & Danimarka & Finlandiya \\
\hline 8 & İrlanda & Danimarka & Finlandiya & Danimarka & Singapur & Singapur \\
\hline 9 & Lüksemburg & Hollanda & Almanya & Almanya & Almanya & Almanya \\
\hline 10 & Danimarka & Almanya & İrlanda & İrlanda & İsrail & Günay Köre \\
\hline
\end{tabular}

Kaynak: The Global Innovation Index, 2015-2020

\section{KÜRESEL İNOVASYON ENDEKSINDE TÜRKI CUMHURIYETLERIN DURUMU}

2015-2020 yılları arasında Türki Cumhuriyetlerin Küresel İnovasyon Endeksinde sergiledikleri durum Tablo 3'de verilmiştir. Tabloda ülkelerin sıralaması endeksteki derecesine göre yapılmştır. Tablo incelendiğinde, 2015 yılında 141 ülke içerisinden Türkiye 58inci, Kazakistan 82inci, Azerbaycan 93üncü, Kırgızistan 109uncu, Tacikistan 114üncü ve Özbekistan ise 122inci sırada yer almıştır. 
Tablo 3: Küresel İnovasyon Endeksinde Türki Cumhuriyetler (2015-2020)

\begin{tabular}{|c|c|c|c|c|c|c|c|c|c|c|c|c|}
\hline \multirow[t]{2}{*}{ Ülke } & \multicolumn{2}{|c|}{ 2015/141 } & \multicolumn{2}{|c|}{$2016 / 128$} & \multicolumn{2}{|c|}{ 2017/127 } & \multicolumn{2}{|c|}{$2018 / 126$} & \multicolumn{2}{|c|}{ 2019/129 } & \multicolumn{2}{|c|}{$2020 / 131$} \\
\hline & G.I. & Puan & G.İ. & Puan & G.İ. & Puan & G.İ. & Puan & G.İ. & Puan & G.İ. & Puan \\
\hline Türkiye & 58 & 37,81 & 42 & 39,03 & 43 & 38,90 & 50 & 37,42 & 49 & 36,95 & 51 & 34,90 \\
\hline Kazakistan & 82 & 31,25 & 75 & 31,51 & 78 & 31,50 & 74 & 31,42 & 79 & 31,03 & 77 & 28,56 \\
\hline Azerbaycan & 93 & 30,10 & 85 & 29,64 & 82 & 30,58 & 82 & 30,20 & 84 & 30,21 & 82 & 27,23 \\
\hline Kırgızistan & 109 & 27,96 & 103 & 26,62 & 95 & 28,01 & 94 & 27,56 & 90 & 28,38 & 94 & 24,51 \\
\hline Özbekistan & 122 & 25,89 & - & - & - & 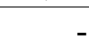 & - & - & - & - & 93 & 24,54 \\
\hline Tacikistan & 114 & 27,46 & 86 & 29,62 & 94 & 28,16 & 101 & 26,51 & 100 & 26,43 & 109 & 22,23 \\
\hline
\end{tabular}

Kaynak: The Global Innovation Index, 2015-2020

Orta ve Güney Asya bölgelerinin ekonomilerinde 2020 yılında Küresel İnovasyon Endeksi sıralamalarında diğer bölgelere göre daha fazla gelişme yaşanmıştır. Türkiye 2015-2020 yılları arasında 7 basamak ilerleyerek 51 inci, Kazakistan 5 basamak ilerleyerek 77inci, Azerbaycan 11 basamak ilerleyerek 82inci, Kırgızistan 15 basamak ilerleyerek 94üncü, Özbekistan 29 basamak ilerleyerek 93üncü ve Tacikistan ise 5 basamak ilerleyerek 109uncu sırada yer almıştır. Özbekistan 2016-2019 yılları arasında endekste yer almamıştır. Ancak, 2020 yılında Kırgızistan’ı da geçerek 93üncü sıradaki yerini almayı başarmıştır. Genel olarak, 2015-2020 yıllar arasında tüm Türki Cumhuriyetlerde pozitif yönde değişimler yaşanmıştır.

Küresel İnovasyon Endeksinin inovasyon girdileri ve çıtıları olmak üzere iki alt endeksten oluştuğu daha önce belirtilmişti. İnovasyon girdi alt endeksini kurumlar, insan sermayesi/araştırma, altyapı, pazar gelişmişliği ve iş gelişmişliği oluşturmaktadır. Küresel İnovasyon Endeksinin girdi alt endeksine göre Türki Cumhuriyetlerin durumu ayrıntılı olarak Tablo 4'te sunulmuştur. Tabloda ülke sıralaması ülkelerin endeksteki derecesine göre yapılmıştır. Tablo incelendiğinde, genel duruma paralel bir durumun ortaya çıktığı görülmektedir. Tüm ülkelerde 2015-2020 yılları arasında olumlu yönde değişimler olduğu özellikle Türkiye (19 basamak ilerlemiş ve 52inci sırada) ve Özbekistan (31 basamak ilerlemiş ve 88inci sırada) önemli ölçüde gelişme kaydetmiştir.

Tablo 4: İnovasyon Girdi Alt Endeksinde Türki Cumhuriyetler (2015-2020)

\begin{tabular}{|c|c|c|c|c|c|c|c|c|c|c|c|c|}
\hline \multirow{2}{*}{ Ülke } & \multicolumn{2}{|c|}{2015} & \multicolumn{2}{|c|}{2016} & \multicolumn{2}{|c|}{2017} & \multicolumn{2}{|c|}{2018} & \multicolumn{2}{|c|}{2019} & \multicolumn{2}{|c|}{2020} \\
\hline & Sira & Puan & Sira & Puan & Sira & Puan & Sira & Puan & Sira & Puan & Sira & Puan \\
\hline Türkiye & 71 & 41,68 & 59 & 42,54 & 68 & 42,32 & 62 & 42,64 & 56 & 45,26 & 52 & 44,36 \\
\hline Kazakistan & 75 & 40,98 & 65 & 41,75 & 64 & 43,15 & 55 & 43,56 & 64 & 43,74 & 60 & 42,78 \\
\hline Azerbaycan & 89 & 37,59 & 81 & 38,39 & 78 & 40,70 & 76 & 40,39 & 77 & 41,59 & 76 & 39,17 \\
\hline Özbekistan & 112 & 33,88 & - & - & - & - & - & - & - & - & 81 & 38,24 \\
\hline Kırgizistan & 94 & 36,57 & 92 & 35,61 & 86 & 38,16 & 85 & 37,99 & 78 & 41,48 & 88 & 36,62 \\
\hline Tacikistan & 115 & 33,39 & 102 & 33,51 & 100 & 35,50 & 104 & 33,04 & 107 & 33,12 & 108 & 31,04 \\
\hline
\end{tabular}

Kaynak: The Global Innovation Index, 2015-2020

Diğer taraftan, inovasyon çıktı alt endeksinde ise bilgi teknolojileri ve yaratıcı çıtılar yer almaktadır. Küresel İnovasyon Endeksinin çıktı alt endeksine göre Türki Cumhuriyetlerin durumu ayrıntılı olarak Tablo 5'te sunulmuştur. Tabloda ülke sıralaması ülkelerin endeksteki derecesine göre yapılmıştır.

Tablo 5: İnovasyon Çıktı Alt Endekside Türki Cumhuriyetler (2015-2020)

\begin{tabular}{|c|c|c|c|c|c|c|c|c|c|c|c|c|}
\hline \multirow{2}{*}{ Ülke } & \multicolumn{2}{|c|}{2015} & \multicolumn{2}{|c|}{2016} & \multicolumn{2}{|c|}{2017} & \multicolumn{2}{|c|}{2018} & \multicolumn{2}{|c|}{2019} & \multicolumn{2}{|c|}{2020} \\
\hline & Sira & Puan & Sira & Puan & Sira & Puan & Sira & Puan & Sira & Puan & Sira & Puan \\
\hline Türkiye & 46 & 33,93 & 37 & 35,52 & 36 & 35,48 & 43 & 32,19 & 49 & 28,64 & 53 & 25,44 \\
\hline Azerbaycan & 103 & 22,62 & 94 & 20,88 & 89 & 20,46 & 87 & 20,00 & 90 & 18,83 & 86 & 15,29 \\
\hline Kazakistan & 107 & 21,52 & 90 & 21,27 & 93 & 19,85 & 91 & 19,28 & 92 & 18,32 & 94 & 14,34 \\
\hline Tacikistan & 106 & 21,54 & 69 & 25,74 & 88 & 20,81 & 88 & 19,98 & 83 & 19,74 & 99 & 13,43 \\
\hline Kırgizistan & 118 & 19,35 & 109 & 17,63 & 104 & 17,86 & 101 & 17,14 & 111 & 15,29 & 107 & 12,40 \\
\hline Özbekistan & 127 & 17,89 & - & - & - & - & - & - & - & - & 118 & 10,83 \\
\hline
\end{tabular}

Kaynak: The Global Innovation Index, 2015-2020

Tablo incelendiğinde, genel sıralama ve girdi endeksine göre sıralamadan farklı olarak Türkiye'den (2015’te 
46ıncı iken 2020'de 53üncü) sonra Azerbaycan (2015'te 103üncü iken 2020'de 861nc1) gelmektedir. Türkiye'nin bu endekste Türki Cumhuriyetler arasında birinci sırada olmakla beraber 2015 yılına göre 7 basamak gerilediği dikkat çekmektedir. Diğer ülkelerde ilerlemelerin olduğu görülmektedir. Özellikle, Azerbaycan (2015-2020 yılları arasında 17 basamak ilerleyerek 861nc1) ve Kazakistan (2015-2020 yılları arasında 13 basamak ilerleyerek 94üncü) önemli gelişme kaydetmiş̧tir.

Türki Cumhuriyetlerin Küresel İnovasyon Endeksindeki durumları her bir kritere göre ayrıntılı olarak incelenmiş ve 2015 ile 2020 yılları arasındaki olumlu veya olumsuz farkları ülkeler bazında tablolaştırılmıştır.

\subsection{Türkiye'nin Durumu}

2015 ile 2020 yılları arasında Türkiye'nin Küresel İnovasyon Endeks göstergeleri Tablo 6'da gösterilmiştir. Tabloda görüldüğü gibi Türkiye kurumlar (-10 fark) ve yaratıcı çıktılar (-13 fark) kriterleri dışındaki alanlarda olumlu yönde değişimler kaydetmiştir.

Tablo 6: Küresel İnovasyon Endeksinde Türkiye

\begin{tabular}{|c|c|c|c|c|c|c|c|}
\hline \multirow{2}{*}{ Temel Kriter } & \multicolumn{3}{|c|}{ Ülke Sıralaması } & \multirow{2}{*}{ Alt Kriter } & \multicolumn{3}{|c|}{ Ülke Sıralaması } \\
\hline & 2015 & 2020 & Fark & & 2015 & 2020 & Fark \\
\hline \multirow{3}{*}{ Kurumlar } & \multirow{3}{*}{84} & \multirow{3}{*}{94} & \multirow{3}{*}{-10} & Politik Çevre & 88 & 77 & 11 \\
\hline & & & & Düzenleyici Ortam & 101 & 108 & -7 \\
\hline & & & & İş Çevresi & 67 & 91 & -24 \\
\hline \multirow{3}{*}{$\begin{array}{l}\text { İnsan Sermayesi ve } \\
\text { Araştırma }\end{array}$} & \multirow{3}{*}{50} & \multirow{3}{*}{42} & \multirow{3}{*}{8} & Eğitim & 58 & 7 & 51 \\
\hline & & & & Yükseköğretim & 57 & 91 & -34 \\
\hline & & & & AR-GE & 40 & 40 & 0 \\
\hline \multirow{3}{*}{ Altyap1 } & \multirow{3}{*}{63} & \multirow{3}{*}{54} & \multirow{3}{*}{9} & Bilgi ve İletişim Teknolojileri & 63 & 49 & 14 \\
\hline & & & & Genel Altyapı & 59 & 57 & 2 \\
\hline & & & & Ekolojik Sürdürülebilirlik & 57 & 55 & 2 \\
\hline \multirow{3}{*}{ Pazar Gelişmiş̧liği } & \multirow{3}{*}{58} & \multirow{3}{*}{28} & \multirow{3}{*}{30} & Kredi & 104 & 66 & 38 \\
\hline & & & & Yatırım & 51 & 44 & 7 \\
\hline & & & & Ticaret, Rekabet ve Pazar Ölçeği & 18 & 7 & 11 \\
\hline \multirow{3}{*}{ İş Dünyasının Gelişmişliği } & \multirow{3}{*}{117} & \multirow{3}{*}{57} & \multirow{3}{*}{60} & Bilgi Çalışanları & 85 & 59 & 26 \\
\hline & & & & İnovasyon Bağlantıları & 110 & 91 & 19 \\
\hline & & & & Bilgi Absorpsiyonu & 127 & 48 & 79 \\
\hline \multirow{3}{*}{ Bilgi ve Teknoloji Çıktıları } & \multirow{3}{*}{60} & \multirow{3}{*}{57} & \multirow{3}{*}{3} & Bilgi Yaratma & 36 & 40 & -4 \\
\hline & & & & Bilgi Etkisi & 83 & 42 & 41 \\
\hline & & & & Bilgi Dağılımı & 108 & 96 & 12 \\
\hline \multirow{3}{*}{ Yaratıcı Çıktılar } & \multirow{3}{*}{37} & \multirow{3}{*}{50} & \multirow{3}{*}{-13} & Maddi Olmayan Duran Varlıklar & 17 & 31 & -14 \\
\hline & & & & Yaratıcı Ürünler ve Hizmetler & 52 & 60 & -8 \\
\hline & & & & Cevrimiçi Yaratıcılık & 59 & 69 & -10 \\
\hline
\end{tabular}

Kaynak: The Global Innovation Index, 2015-2020

\subsection{Azerbaycan'in Durumu}

Tablo7'de Azerbaycan'ın 2015-2020 y11larına ait Küresel İnovasyon Endeks göstergeleri verilmiştir. Azerbaycan da iş dünyasının gelişmişliği kriterinde 40 basamak ilerleyerek 2020 yılında 96ıncı sırada yer almıştır.

Tablo 7: Küresel İnovasyon Endeksinde Azerbaycan

\begin{tabular}{|c|c|c|c|c|c|c|c|}
\hline \multirow{2}{*}{ Temel Kriter } & \multicolumn{3}{|c|}{ Ülke Sıralaması } & \multirow{2}{*}{ Alt Kriter } & \multicolumn{3}{|c|}{ Ülke Sıralaması } \\
\hline & 2015 & 2020 & Fark & & 2015 & 2020 & Fark \\
\hline \multirow{3}{*}{ Kurumlar } & \multirow{3}{*}{81} & \multirow{3}{*}{59} & \multirow{3}{*}{22} & Politik Çevre & 94 & 73 & 21 \\
\hline & & & & Düzenleyici Ortam & 107 & 80 & 27 \\
\hline & & & & İş Çevresi & 51 & 33 & 18 \\
\hline \multirow{3}{*}{$\begin{array}{l}\text { İnsan Sermayesi ve } \\
\text { Araştırma }\end{array}$} & \multirow{3}{*}{100} & \multirow{3}{*}{89} & \multirow{3}{*}{11} & Eğitim & 114 & 84 & 30 \\
\hline & & & & Yükseköğretim & 97 & 82 & 15 \\
\hline & & & & AR-GE & 62 & 91 & -29 \\
\hline \multirow{3}{*}{ Altyap1 } & \multirow{3}{*}{78} & \multirow{3}{*}{85} & \multirow{3}{*}{-7} & Bilgi ve İletişim Teknolojileri & 69 & 68 & 1 \\
\hline & & & & Genel Altyap1 & 107 & 120 & -13 \\
\hline & & & & Ekolojik Sürdürülebilirlik & 59 & 73 & -14 \\
\hline Pazar Gelișmișliği & 47 & 36 & 11 & Kredi & 83 & 39 & 44 \\
\hline
\end{tabular}


Uluslararası Akademik Çalışmalar Dergisi, 2021, Cilt: 1, Sayı: 1, ss.12-22 - International Journal of Academic Studies, 2021, Vol.1, Issue.1, pp.12-22

\begin{tabular}{|c|c|c|c|c|c|c|c|}
\hline & & & & Yatırım & 10 & 23 & -13 \\
\hline & & & & Ticaret, Rekabet ve Pazar Ölçeği & 95 & 86 & 9 \\
\hline \multirow{3}{*}{ İş Dünyasının Gelişmişliği } & \multirow{3}{*}{136} & \multirow{3}{*}{96} & \multirow{3}{*}{40} & Bilgi Çalışanları & 110 & 84 & 26 \\
\hline & & & & İnovasyon Bağlantıları & 133 & 67 & 66 \\
\hline & & & & Bilgi Absorpsiyonu & 134 & 119 & 15 \\
\hline \multirow{3}{*}{ Bilgi ve Teknoloji Çıktıları } & \multirow{3}{*}{108} & \multirow{3}{*}{118} & \multirow{3}{*}{-10} & Bilgi Yaratma & 130 & 98 & 32 \\
\hline & & & & Bilgi Etkisi & 94 & 112 & -18 \\
\hline & & & & Bilgi Dağılımı & 107 & 115 & -8 \\
\hline \multirow{3}{*}{ Yaratıcı Çıktılar } & \multirow{3}{*}{93} & \multirow{3}{*}{65} & \multirow{3}{*}{28} & Maddi Olmayan Duran Varlıklar & 91 & 56 & 35 \\
\hline & & & & Yaratıcı Ürünler ve Hizmetler & 68 & 87 & -19 \\
\hline & & & & Çevrimiçi Yaratıcılık & 92 & 67 & 25 \\
\hline
\end{tabular}

Kaynak: The Global Innovation Index, 2015-2020

Bununla birlikte kurumlar ve yaratıcı çıktılar kriterlerinde de gelişmeler yaşanmıştır. Diğer taraftan, bilgi ve teknoloji çıktıları (-10 fark) ve altyapı (-7 fark) kriterlerinde en düşük performans sergilemiştir. Azerbaycan temel kriterler içerisinden pazar gelişmişliği kriterinde en iyi (36ıncı sırada) durumda olduğu söylenebilir.

\subsection{Kazakistan' in Durumu}

Tablo 8'de Kazakistan'ın 2015-2020 yıllarına ait Küresel İnovasyon Endeks göstergeleri verilmiştir. Kazakistan pazar gelişmişliği kriterlerinde 43 basamak ilerleyerek 43üncü sırada yer almış ve en çok gelişme yaşanan alan bu olmuştur. Diğer taraftan, altyapı (-12) ve insan sermayesi (-2) kriterlerinde olumsuz gelişme göstermiştir. Kazakistan temel kriterler içerisinden kurumlar kriterinde en iyi (49ncu sırada) durumdadır.

Tablo 8: Küresel İnovasyon Endeksinde Kazakistan

\begin{tabular}{|c|c|c|c|c|c|c|c|}
\hline \multirow{2}{*}{ Temel Kriter } & \multicolumn{3}{|c|}{ Ülke Sıralaması } & \multirow{2}{*}{ Alt Kriter } & \multicolumn{3}{|c|}{ Ülke Sıralaması } \\
\hline & 2015 & 2020 & Fark & & 2015 & 2020 & Fark \\
\hline \multirow{3}{*}{ Kurumlar } & \multirow{3}{*}{67} & \multirow{3}{*}{49} & \multirow{3}{*}{18} & Politik Çevre & 98 & 68 & 30 \\
\hline & & & & Düzenleyici Ortam & 71 & 48 & 23 \\
\hline & & & & İş Çevresi & 35 & 31 & 4 \\
\hline \multirow{3}{*}{$\begin{array}{l}\text { İnsan Sermayesi ve } \\
\text { Araştırma }\end{array}$} & \multirow{3}{*}{66} & \multirow{3}{*}{68} & \multirow{3}{*}{-2} & Eğitim & 49 & 76 & -27 \\
\hline & & & & Yükseköğretim & 99 & 55 & 44 \\
\hline & & & & AR-GE & 52 & 57 & -5 \\
\hline \multirow{3}{*}{ Altyap1 } & \multirow{3}{*}{54} & \multirow{3}{*}{66} & \multirow{3}{*}{-12} & Bilgi ve İletişim Teknolojileri & 33 & 42 & -9 \\
\hline & & & & Genel Altyap1 & 54 & 69 & -15 \\
\hline & & & & Ekolojik Sürdürülebilirlik & 104 & 103 & 1 \\
\hline \multirow{3}{*}{ Pazar Gelişmişliği } & \multirow{3}{*}{96} & \multirow{3}{*}{53} & \multirow{3}{*}{43} & Kredi & 108 & 82 & 26 \\
\hline & & & & Yatırım & 71 & 28 & 43 \\
\hline & & & & Ticaret, Rekabet ve Pazar Ölçeği & 79 & 50 & 29 \\
\hline \multirow{3}{*}{ İş Dünyasının Gelişmişliği } & \multirow{3}{*}{110} & \multirow{3}{*}{71} & \multirow{3}{*}{39} & Bilgi Çalışanları & 68 & 52 & 16 \\
\hline & & & & İnovasyon Bağlantıları & 128 & 124 & 4 \\
\hline & & & & Bilgi Absorpsiyonu & 115 & 91 & 24 \\
\hline \multirow{3}{*}{ Bilgi ve Teknoloji Çıktıları } & \multirow{3}{*}{96} & \multirow{3}{*}{80} & \multirow{3}{*}{16} & Bilgi Yaratma & 80 & 72 & 8 \\
\hline & & & & Bilgi Etkisi & 70 & 97 & -27 \\
\hline & & & & Bilgi Dağılımı & 109 & 76 & 33 \\
\hline \multirow{3}{*}{ Yaratıcı Çıktılar } & \multirow{3}{*}{117} & \multirow{3}{*}{105} & \multirow{3}{*}{12} & Maddi Olmayan Duran Varlıklar & 121 & 107 & 14 \\
\hline & & & & Yaratıcı Ürünler ve Hizmetler & 86 & 96 & -10 \\
\hline & & & & Çevrimiçi Yaratıcılık & 97 & 79 & 18 \\
\hline
\end{tabular}

Kaynak: The Global Innovation Index, 2015-2020

\subsection{Kirgizistan'ın Durumu}

Tablo 9'da Kırgızistan'ın 2015-2020 yıllarına ait Küresel İnovasyon Endeks göstergeleri verilmiştir. Kırgızistan altyapı (17 basamak), yaratıcı çıktılar (15 basamak) ve kurumlar (13 basamak) kriterlerinde gelişme göstermiştir. Ancak pazarın gelişmişliği (-10) iş dünyasının gelişmişliği (-6) ve insan sermayesi ve araştırma (3-) kriterlerinde ise düşüş söz konusudur. 
Tablo 9: Küresel İnovasyon Endeksinde Kırgızistan

\begin{tabular}{|c|c|c|c|c|c|c|c|}
\hline \multirow{2}{*}{ Temel Kriter } & \multicolumn{3}{|c|}{ Ülke Sıralaması } & \multirow{2}{*}{ Alt Kriter } & \multicolumn{3}{|c|}{ Ülke Sıralaması } \\
\hline & 2015 & 2020 & Fark & & 2015 & 2020 & Fark \\
\hline \multirow{3}{*}{ Kurumlar } & \multirow{3}{*}{105} & \multirow{3}{*}{92} & \multirow{3}{*}{13} & Siyasi Ortam & 117 & 114 & 3 \\
\hline & & & & Düzenleyici Ortam & 103 & 93 & 10 \\
\hline & & & & İş Ortamı & 98 & 66 & 32 \\
\hline \multirow{3}{*}{$\begin{array}{l}\text { İnsan Sermayesi ve } \\
\text { Araştırma }\end{array}$} & \multirow{3}{*}{70} & \multirow{3}{*}{73} & \multirow{3}{*}{-3} & Eğitim & 27 & 33 & -6 \\
\hline & & & & Yükseköğretim & 77 & 74 & 3 \\
\hline & & & & AR-GE & 107 & 109 & -2 \\
\hline \multirow{3}{*}{ Altyap1 } & \multirow{3}{*}{114} & \multirow{3}{*}{97} & \multirow{3}{*}{17} & Bilgi ve İletişim Teknolojileri & 102 & 86 & 16 \\
\hline & & & & Genel Altyap1 & 101 & 85 & 16 \\
\hline & & & & Ekolojik Sürdürülebilirlik & 128 & 112 & 16 \\
\hline \multirow{3}{*}{ Pazarın Gelişmişliği } & \multirow{3}{*}{56} & \multirow{3}{*}{66} & \multirow{3}{*}{-10} & Kredi & 41 & 34 & 7 \\
\hline & & & & Yatırım & 92 & 60 & 32 \\
\hline & & & & Ticaret, Rekabet ve Pazar Ölçeği & 74 & 110 & -36 \\
\hline \multirow{3}{*}{ İş Dünyasının Gelişmişliği } & \multirow{3}{*}{99} & \multirow{3}{*}{105} & \multirow{3}{*}{-6} & Bilgi İşçileri & 51 & 92 & -41 \\
\hline & & & & İnovasyon Bağlantıları & 131 & 126 & 5 \\
\hline & & & & Bilgi Absorpsiyonu & 108 & 90 & 18 \\
\hline \multirow{3}{*}{ Bilgi ve Teknoloji Çıktıları } & \multirow{3}{*}{88} & \multirow{3}{*}{81} & \multirow{3}{*}{7} & Yaratılan Bilgi & 64 & 59 & 5 \\
\hline & & & & Bilgi Etkisi & 53 & 103 & -50 \\
\hline & & & & Bilgi Dağılımı & 122 & 93 & 29 \\
\hline \multirow{3}{*}{ Yaratıcı Çıktılar } & \multirow{3}{*}{132} & \multirow{3}{*}{117} & \multirow{3}{*}{15} & Maddi Olmayan Duran Varlıklar & 131 & 121 & 10 \\
\hline & & & & Yaratıcı Ürün ve Hizmetler & 109 & 106 & 3 \\
\hline & & & & Çevrimiçi (online) Yaratıcılık & 112 & 102 & 10 \\
\hline
\end{tabular}

Kaynak: The Global Innovation Index, 2015-2020

\subsection{Tacikistan'ın Durumu}

Tablo 10'da Tacikistan'ın 2015-2020 yıllarına ait Küresel İnovasyon Endeks göstergeleri verilmiştir. Tacikistan yaratıcı çıktılar (17 basamak) ve altyapı (12 basamak) kriterlerinde gelişme göstermiştir. Ancak, pazar gelişmişliği (-20), iş dünyasının gelişmişliği (-20), bilgi ve teknoloji çıktıları (-7) kriterlerinde tam tersi büyük oranda düşüş yaşanmıştır. Aynı zamanda, insan sermayesi ve araştırma kriterinde gerileme olduğu görülmektedir.

Tablo 10: Küresel İnovasyon Endeksinde Tacikistan

\begin{tabular}{|c|c|c|c|c|c|c|c|}
\hline \multirow[t]{2}{*}{ Temel Kriter } & \multicolumn{3}{|c|}{ Ülke Sıralaması } & \multirow[t]{2}{*}{ Alt Kriter } & \multicolumn{3}{|c|}{ Ülke Sıralaması } \\
\hline & 2015 & 2020 & Fark & & 2015 & 2020 & Fark \\
\hline \multirow{3}{*}{ Kurumlar } & \multirow{3}{*}{127} & \multirow{3}{*}{118} & \multirow{3}{*}{9} & Politik Çevre & 130 & 126 & 4 \\
\hline & & & & Düzenleyici Ortam & 112 & 118 & -6 \\
\hline & & & & İş Çevresi & 128 & 105 & 23 \\
\hline \multirow{3}{*}{$\begin{array}{l}\text { İnsan Sermayesi ve } \\
\text { Araştırma }\end{array}$} & \multirow{3}{*}{86} & \multirow{3}{*}{87} & \multirow{3}{*}{-1} & Eğitim & 75 & 70 & 5 \\
\hline & & & & Yükseköğretim & 70 & 86 & -16 \\
\hline & & & & AR-GE & 112 & 112 & 0 \\
\hline \multirow{3}{*}{ Altyap 1} & \multirow{3}{*}{135} & \multirow{3}{*}{123} & \multirow{3}{*}{12} & Bilgi ve İletişim Teknolojileri & 138 & 119 & 19 \\
\hline & & & & Genel Altyap1 & 136 & 122 & 14 \\
\hline & & & & Ekolojik Sürdürülebilirlik & 88 & 95 & -7 \\
\hline \multirow{3}{*}{ Pazar Gelişmiş̧liği } & \multirow{3}{*}{40} & \multirow{3}{*}{60} & \multirow{3}{*}{-20} & Kredi & 61 & 22 & 39 \\
\hline & & & & Yatırım & 12 & 60 & -48 \\
\hline & & & & Ticaret, Rekabet ve Pazar Ölçeği & 100 & 109 & -9 \\
\hline \multirow{3}{*}{ İş Dünyasının Gelişmişliği } & \multirow{3}{*}{108} & \multirow{3}{*}{128} & \multirow{3}{*}{-20} & Bilgi Çalışanları & 99 & 117 & -18 \\
\hline & & & & İnovasyon Bağlantıları & 101 & 112 & -11 \\
\hline & & & & Bilgi Absorpsiyonu & 92 & 116 & -24 \\
\hline \multirow{3}{*}{ Bilgi ve Teknoloji Çıktıları } & \multirow{3}{*}{70} & \multirow{3}{*}{77} & \multirow{3}{*}{-7} & Bilgi Yaratma & 46 & 55 & -9 \\
\hline & & & & Bilgi Etkisi & 91 & 95 & -4 \\
\hline & & & & Bilgi Dağılımı & 98 & 90 & 8 \\
\hline \multirow{3}{*}{ Yaratıcı Çıktılar } & \multirow{3}{*}{130} & \multirow{3}{*}{113} & \multirow{3}{*}{17} & Maddi Olmayan Duran Varlıklar & 127 & 120 & 7 \\
\hline & & & & Yaratıcı Ürünler ve Hizmetler & 111 & 85 & 26 \\
\hline & & & & Çevrimiçi Yaratıcılık & 117 & 99 & 18 \\
\hline
\end{tabular}


Kaynak: The Global Innovation Index, 2015-2020

\section{6. Özbekistan'ın Durumu}

Tablo 11'de Özbekistan'ın 2015-2020 y1llarına ait Küresel İnovasyon Endeks göstergeleri verilmiştir. Özbekistan pazar gelişmişliği (58 basamak) kriterinde en çok gelişme gerçekleştirdiğini görmekteyiz. Bununla birlikte, altyapı, kurumlar, iş dünyasının gelişmişliği ve yaratıcı çıktılar kriterlerinde de gelişme yaşandığını dikkat çekmektedir. Ancak bilgi ve teknoloji çıktıları (-29 fark) kriterinde ise büyük bir seviyede düşüşsöz konusudur.

Tablo 11: Küresel İnovasyon Endeksinde Özbekistan

\begin{tabular}{|c|c|c|c|c|c|c|c|}
\hline \multirow{2}{*}{ Temel Kriter } & \multicolumn{3}{|c|}{ Ülke Sıralaması } & \multirow{2}{*}{ Alt Kriter } & \multicolumn{3}{|c|}{ Ülke Sıralaması } \\
\hline & 2015 & 2020 & Fark & & 2015 & 2020 & Fark \\
\hline \multirow{3}{*}{ Kurumlar } & \multirow{3}{*}{106} & \multirow{3}{*}{95} & \multirow{3}{*}{11} & Politik Çevre & 115 & 98 & 17 \\
\hline & & & & Düzenleyici Ortam & 121 & 107 & 14 \\
\hline & & & & İș Çevresi & 76 & 72 & 4 \\
\hline \multirow{3}{*}{$\begin{array}{l}\text { İnsan Sermayesi ve } \\
\text { Araştırma }\end{array}$} & \multirow{3}{*}{76} & \multirow{3}{*}{77} & \multirow{3}{*}{-1} & Eğitim & 29 & 52 & -23 \\
\hline & & & & Yükseköğretim & 95 & 73 & 22 \\
\hline & & & & AR-GE & 92 & 94 & -2 \\
\hline \multirow{3}{*}{ Altyap 1} & \multirow{3}{*}{101} & \multirow{3}{*}{72} & \multirow{3}{*}{29} & Bilgi ve İletişim Teknolojileri & 93 & 72 & 21 \\
\hline & & & & Genel Altyap 1 & 73 & 41 & 32 \\
\hline & & & & Ekolojik Sürdürülebilirlik & 132 & 101 & 31 \\
\hline \multirow{3}{*}{ Pazar Gelişmiş̧liği } & \multirow{3}{*}{85} & \multirow{3}{*}{27} & \multirow{3}{*}{58} & Kredi & 87 & 57 & 30 \\
\hline & & & & Yatırım & 115 & 8 & 107 \\
\hline & & & & Ticaret, Rekabet ve Pazar Ölçeği & 42 & 108 & -66 \\
\hline \multirow{3}{*}{ İş Dünyasının Gelişmişliği } & \multirow{3}{*}{138} & \multirow{3}{*}{127} & \multirow{3}{*}{11} & Bilgi Çalışanları & 135 & 91 & 44 \\
\hline & & & & İnovasyon Bağlantıları & 138 & 128 & 10 \\
\hline & & & & Bilgi Absorpsiyonu & 27 & 109 & -82 \\
\hline \multirow{3}{*}{ Bilgi ve Teknoloji Çıktıları } & \multirow{3}{*}{61} & \multirow{3}{*}{90} & \multirow{3}{*}{-29} & Bilgi Yaratma & 75 & 84 & -9 \\
\hline & & & & Bilgi Etkisi & 38 & 49 & -11 \\
\hline & & & & Bilgi Dağılımı & $\mathrm{n} / \mathrm{a}$ & 131 & - \\
\hline \multirow{3}{*}{ Yaratıcı Çıktılar } & \multirow{3}{*}{138} & \multirow{3}{*}{127} & \multirow{3}{*}{11} & Maddi Olmayan Duran Varlıklar & 136 & 128 & 8 \\
\hline & & & & Yaratıcı Ürünler ve Hizmetler & 93 & 75 & 18 \\
\hline & & & & Çevrimiçi Yaratıcılık & 126 & 126 & 0 \\
\hline
\end{tabular}

Kaynak: The Global Innovation Index, 2015-2020

\section{SONUÇ}

Günümüzde hem yerel, hem de küresel piyasalarda rekabetin artması, tüketicilerin istek ve ihtiyaçlarının değişmesi, ürünlerin ömürlerinin kısalması, dış çevrede yaşanan sürekli değişim ve gelişmeler, teknolojinin sunduğu imkânlar işletmeleri daha yenilikçi olmaya ve daha çok inovasyona odaklanmaya itmektedir. İşletmeler artık yerel işletmelerle değil, ulusal sınırların kalktığı dünya pazarında yer alan işletmelerle rekabet etmek zorunda kalmaktadırlar. Söz konusu değişen pazar özellikleri yeni değerleri ve beklentileri de ortaya çıkarmıştır. Bunlar; yüksek düzeyde kaliteli ürün sunma, ürüne değer ekleme, tam zamanında mükemmel hizmet sunma, yenilik yaratma, rakiplerin ürününden farklılaştırılmış yeni ürün geliştirme olarak ifade edilebilmektedir. Bugün inovasyon tüm dünyada gelişim göstermektedir. Ancak, bu gelişmelere rağmen ortaya çıkan yeni engeller küresel inovasyon için önemli düzeyde risk oluşturmaktadır.

Birkaç yıl önce inovasyon faaliyetleri ve inovasyon politikaları yüksek gelirli ekonomilerde gelişim göstermişti. Bugün hem gelişmiş, hem de gelişmekte olan ekonomiler ekonomik ve sosyal kalkınmayı arttırmak için inovasyonu sıkı bir şekilde gündemlerine almaya başlamışlardır. Günümüzde inovasyon ve bilgi, ekonomik ve sosyal kalkınmanın temel unsurlarından biri olarak öne çıkmaktadır. Bu yüzden, dünyadaki birçok ülke inovasyon konusunda strateji ve politkalar geliştirmeye çaba göstermektedir. Yani, ulusal sınırları aşarak uluslararası düzeyde rekabet edebilmek, ülkenin ekonomisini geliştirmek ve ülkenin refah düzeyini artırmak açısından inovasyon kritik kavram olarak ortaya çıkmaktadır.

Her yıl Küresel İnovasyon Endeksi, dünya çapında yaklaşık 130 ekonominin inovasyon performansını sıralamaktadır. Uluslararası araştırmaların gösterdiği gibi dünyadaki birçok ülke inovasyon konusunda farklı seviyelerde sorunlar yaşamaktadırlar. Orta Asya Türki Cumhuriyetleri Küresel İnovasyon Endeksinde 2015-2020 
yıllar arasında birçok bileşende gelişme göstermiştir. Genel olarak, incelenen ülkelerin yenilikçi olma potansiyeline sahip olduğu ancak henüz inovasyon konusundaki mevcut durumlarının yüksek ve istenilen düzeyde olmadığı anlaşılmaktadır. Türki Cumhuriyetlerinin durumuna bakıldığında, Türkiye'nin ve Kazakistan'ın diğer ülkelere göre durumunun daha iyi olduğu görülmektedir. İnovasyon konusunda ele alınan ülkeler arasında en kötü durumda olanın Tacikistan'ın olduğu anlaşılmaktadır. Özellikle Tacikistan'ın insan sermayesi ve araştırma, pazar gelişmişliği, iş dünyasının gelişmiş̧liği ve bilgi/teknoloji çıktıları konularına daha çok önem vermesi gerekmektedir. Bununla birlikte, Kazakistan ve Kırgızistan'ın yaratıcı çıktılar bileşeninde sorunlar yaşadıkları görülmektedir. Kırgızistan'ın yenilikçilik gelişimi, günümüzün en önemli sorunlarından biri olmaya devam etmektedir. Kırgızistan, Azerbaycan, Tacikistan ve Özbekistan'ın inovasyon konusunda diğer Türki Cumhuriyetlerle karşılaştırıldığında daha fazla çaba göstermesi gerekmektedir.

Hem ülkeler, hem de işletmeler için küresel rekabet yarışında anahtar role sahip olan inovasyon, karmaşık özellik taşıyan ve birçok kurumun yer aldığı etkileşimli bir süreçtir. İşletmeler, küresel pazarlarda yaşamlarını sürdürmek ve ayakta kalmak istiyorlarsa, yeniliği ve inovasyonu sistematik bir şekilde yönetim altına almalı ve gerekli altyapıyı (kurumsal/hukuki) hazırlayarak, inovasyon için elverişli bir ortam yaratmaya çalışmalıdırlar.

\section{KAYNAKÇA}

BASKARA, Shruthi \& MEHTA, Khanjan (2016), "What is Innovation And Why? Your Perspective From Resource Constrained Environments”, Technovation, Vol. 52, Issue 53, pp 4-17.

COSTELlO, Tom \& PROHASKA, Beverly (2013), “Innovation”, IT Professional, 15(3), 62-64.

DUTTA, Soumitra., LANVIN, Bruno \& WUNSCH-VINCENT, Sacha (2014), The Global Innovation Index 2014: The Human Factor in Innovation. https://www.wipo.int/edocs/pubdocs/en/economics/gii/gii_2014.pdf (Erişim Tarihi: 25.04.2021).

DUTTA, Soumitra., LANVIN, Bruno \& WUNSCH-VINCENT, Sacha (2015), The Global Innovation Index 2015: Effective Innovation Policies for Development. https://www.wipo.int/edocs/pubdocs/en/wipo_gii 2015.pdf (Erişim Tarihi: 25.04.2021).

DUTTA, Soumitra., LANVIN, Bruno \& WUNSCH-VINCENT, Sacha (2016), The Global Innovation Index 2016 Winning with Global Innovation. https://www.wipo.int/edocs/pubdocs/en/wipo pub gii_2016.pdf (Erişim Tarihi: 25.04.2021).

DUTTA, Soumitra., LANVIN, Bruno \& WUNSCH-VINCENT, Sacha (2017), The Global Innovation Index 2017 Innovation Feeding the World. https://www.wipo.int/edocs/pubdocs/en/wipo_pub_gii_2017.pdf (Erişim Tarihi: 25.04.2021).

DUTTA, Soumitra., LANVIN, Bruno \& WUNSCH-VINCENT, Sacha (2018), Global Innovation Index 2018: Energizing the World with İnnovation. https://www.wipo.int/edocs/pubdocs/en/wipo pub gii_2018.pdf (Erişim Tarihi: 25.04.2021).

DUTTA, Soumitra., LANVIN, Bruno \& WUNSCH-VINCENT, Sacha (2019), Global Innovation Index 2019: Creating Healthy Lives-The Future of Medical Innovation. https://www.wipo.int/edocs/pubdocs/en/wipo_pub_gii_2019.pdf (Erişim Tarihi: 25.04.2021).

GËRGURI, Shqipe, REXHEPI, Gadaf \& RAMADANI, Veland (2013), "Innovation Strategies and Competitive Advantages”, Modern Economics: Problems, Trends, Prospects, Vol.8, Issue 1, pp. 10-26

IONESCU, Alexandru \& DUMITRU, Nicoleta Rossela (2015), "The Role of Innovation In Creating The Company's Competitive Advantage”, EcoForum, Vol.1, Issue 6, pp 99-104.

KUCZMARKSI, Tomas (2003), “What is Innovation? And Why Aren't Companies Doing More of It??", The Journal of Consumer Marketing, Vol. 20, Issue 6, pp 536-541.

MCDANIEL, Bruce (2002), Entreprneurship and Innovation: An Economic Approach, M.E Sharpe: London. 1st Edition.

POPA, Ioan Lala, PREDA, Gheorghe \& BOLDE, Monica (2010), “A Theoretical Approach of The Concept of 
Innovation”, Description: Managerial Challenges of the Contemporary Society 29, Faculty of Economics and Business Administration, Babes-Bolyai University. http://conference.ubbcluj.ro/mccs/RePEc/bbu/wpaper/151156.pdf (Erişim Tarihi: 25.04.2021).

Ramadani, V. ve Gerguri, S. (2011). Innovations: Principles and Strategies. Strategic Change, 20, 101-110.

RAMADANI, Veland \& SHQIPE, Gerguri (2010), “Innovations: principles and strategiest”, Strategic Change, Vol. 20, pp 101-110.

ÜNAL, Aslihan ve KILINÇ, İzzet (2016), “İnovasyon Yönetimi”, Girişimcilik ve İnovasyon Yonetimi (Ed. Kahraman Çatı), Nobel, Ankara, ss. 99-134. 